\title{
LUT
}

University

Orienting toward sales growth? Decomposing the variance attributed to three fundamental organizational strategic orientations

Wales William, Beliaeva Tatiana, Shirokova Galina, Stettler Tatiana R., Gupta Vishal K.

This is a Final draft version of a publication

published by Elsevier

in Journal of Business Research

DOI: $\quad 10.1016 /$ j.jbusres.2018.12.019

Copyright of the original publication: (c) 2018 Elsevier Inc.

Please cite the publication as follows:

Wales, W., Beliaeva, T., Shirokova, G., Stettler, T.R., Gupta, V.K. (2018). Journal of Business Research, pp. 1-30. DOI: 10.1016/j.jbusres.2018.12.019

This is a parallel published version of an original publication. This version can differ from the original published article. 


\section{Orienting toward sales growth? Decomposing the variance attributed to three fundamental organizational strategic orientations}

William Wales ${ }^{a, *}$, Tatiana Beliaeva ${ }^{\text {b, c }}$, Galina Shirokova ${ }^{\text {b }}$, Tatiana R. Stettler $^{\text {d }}$, Vishal K. Gupta ${ }^{\text {e }}$

${ }^{a}$ University at Albany-SUNY, School of Business, 1400 Washington Ave, Albany, NY 12222, USA, e-mail: wwales@albany.edu, Tel. 1 (518) 429-9479

${ }^{\mathrm{b}}$ St. Petersburg University, Graduate School of Management, 3 Volkhovsky pereulok, St. Petersburg, 199004, Russia, e-mails: t.beliaeva@gsom.pu.ru; shirokova@gsom.pu.ru.

${ }^{c}$ Lappeenranta University of Technology, School of Business and Management, P.O. Box 20, FI-53851 Lappeenranta, Finland, e-mail: Tatiana.Beliaeva@student.lut.fi

${ }^{\mathrm{d}}$ Kent State University, College of Business Administration, 475 Terrace Drive, Kent, Ohio 44242-0001, USA, e-mail: tstettle@kent.edu

e The University of Alabama, Culverhouse College of Commerce, 171 Alston, Tuscaloosa, AL 35406, USA, e-mail: vkgupta@ cba.ua.edu

\section{Acknowledgements}

The authors would like to thank Dr. Diemo Urbig for generously sharing a program for the statistical software STATA with the research team to implement the commonality analysis.

\section{Funding}

This research did not receive any specific grant from funding agencies in the public, commercial, or not-for-profit sectors.

Declarations of interest: none.

* Corresponding author 


\title{
Orienting Toward Sales Growth? Decomposing the Variance Attributed to Three Fundamental Organizational Strategic Orientations
}

\begin{abstract}
While firm strategic orientations have received considerable attention, most research has focused on singular orientations without considering their complementarity for firm's outcomes. In this study, we decompose the unique and complementary variance of several strategic orientations - market (MO), entrepreneurial (EO), and learning orientation (LO) on firm sales growth. Our investigation of the individual unique effects of these orientations reveals that, within our cross-national random sample of 221 firms from Finland and Russia, sales growth is principally driven by EO. Second, our results show, that the complementary or shared effects of EO, MO, and LO explain a significant portion of the variance in sales growth. Building upon past research, we offer evidence that a higher-order constructproactive learning culture- is supported at the intersection of these fundamental strategic orientations with important implications for future scholarship examining multiple strategic orientations.
\end{abstract}

\section{Keywords:}

Market orientation; entrepreneurial orientation; learning orientation; proactive learning culture; firm growth; commonality analysis. 


\section{Orienting Toward Sales Growth? Decomposing the Variance Attributed to Three Fundamental Organizational Strategic Orientations}

\section{Introduction}

Given the ever evolving nature of the economic environment, firms are constantly striving for new opportunities in the marketplace so that they can identify paths to grow and thrive (Rothaermel, 2008). To this end, much attention is focused on firms' strategic orientations, or the strategic philosophies, processes, and behaviors of a company that enable the organization to achieve superior performance (Gatignon \& Xuereb, 1997; Noble, Sinha, \& Kumar, 2002). Prior literature suggests that several overarching strategic orientations exist. These orientations emphasize a market focus and providing superior value for customers (market orientation (MO); Narver \& Slater, 1990), an entrepreneurial focus that entails developing and launching new products and services (entrepreneurial orientation (EO); Covin \& Slevin, 1989), or the creation and use of knowledge by organizations in a manner that challenges existing assumptions and beliefs (learning orientation (LO); Sinkula, Baker, \& Noordewier, 1997).

The development of strategic orientations within a company can have a significant effect on their performance. While the majority of the literature has focused on the effects of a single strategic orientation in isolation (e.g., Keith \& Stephen, 2006; Kirca, Jayachandran, \& Bearden, 2005; Rauch, Wiklund, Lumpkin, \& Frese, 2009), previous studies observe that a single orientation alone may be insufficient for the effective achievement of firm performance (Bhuian, Menguc, \& Bell, 2005; Hakala, 2011). That is, a combination of strategic orientations might enable organizations to perform better (Deutscher, Zapkau, Schwens, Baum, \& Kabst, 2016; Gnizy, Baker, \& Grinstein, 2014; Lonial \& Carter, 2015). Yet, our understanding of multiple strategic orientations and their combination is still in its early stages (Hakala, 2011), with many approaches being considered. For instance, studies 
have examined separate individual effects of different strategic orientations on firm performance (e.g., Farrell \& Oczkowski, 2002; Kropp, Lindsay, \& Shoham, 2006; Laukkanen, Nagy, Hirvonen, Reijonen, \& Pasanen, 2013), joint complementary effects of orientations tested as interactions (e.g., Atuahene-Gima, Slater, \& Olson, 2005; Boso, Cadogan, \& Story, 2012) and higher-order constructs (e.g., Hult, Ketchen, \& Arrfelt, 2007; Lonial \& Carter, 2015), configurations of orientations (e.g., Hakala \& Kohtamäki, 2011; Ho, Plewa, \& Lu, 2016), and mediating effects between orientations (e.g., Dutta, Gupta, \& Chen, 2016; Nguyen, Barrett, \& Fletcher, 2006). While these approaches have provided a wealth of insights, research has yet to consider or investigate the common and shared variance attributable to each orientation upon specific and highly relevant firm performance considerations such as sales growth. This line of inquiry provides a basis for increased insight about which strategic orientations may most influence key firm outcomes.

At the heart of this research is the question: How do firms best strategically orient themselves to achieve sales growth? To answer this question, we decompose the variance across three fundamental organizational strategic orientations. Our research question then may be more specifically stated as: How do market, entrepreneurial, and learning orientations individually and jointly (complementarily) contribute to the explanation of firms' total variance in sales growth? Answering this question, our research contributes to the existing literature on strategic orientations in several ways. A principle contribution is that beyond the combined effects of market, entrepreneurial and learning orientations on firm performance (Deutscher et al., 2016; Dutta et al., 2016; Gnizy et al., 2014; Hult, Snow, \& Kandemir, 2003; Lonial \& Carter, 2015), we assess performance (i.e. sales growth) variance attributable to unique and bilaterally shared effects. This analytic approach is based on commonality analysis (Lomberg, Urbig, Stöckmann, Marino, \& Dickson, 2017) and provides much needed comparative insights into the relationships between these strategic orientations and firm 
performance. Thereby, we estimate both individual and joint contributions of market, entrepreneurial and learning orientations to superior firm sales growth.

A second principle contribution stems from our investigation of the complementarity of market, entrepreneurial, and learning orientations. Complementarity strategies have previously been viewed either as "independent pieces that 'complete' each other" or as mutually dependent practices that reinforce each other and create synergistic performance effects (Tanriverdi \& Lee, 2008, p. 384). Our research examines support for the conceptual assertion of a higher-order dynamic capability at the intersection of the three strategic orientations, termed proactive learning culture (PLC) by Gnizy et al. (2014), and viewed as a 'three-legged' bench in which each of the strategic orientations represents an essential 'pillar' or 'leg' and, at the same time, a source of synergistic effects. Methodologically, Gnizy et al. (2014) test alternative models and find that PLC explains variance in the success of foreign launch equal to or greater than that explained by its first orders (EO, MO, and LO). We go one step further and illustrate how this variance can be attributed to unique or shared effects of the three dimensions. Additionally, we consider the concept of PLC within a different setting than Gnizy et al. (2014) and propose that the relative weight of these orientations in their relationships with firm outcomes is a function of firms' competitive situations.

An additional contribution to the literature is that we extend and apply commonality analysis within a unique, multi-orientation research setting and demonstrate how the analytical technique can provide much needed insights within strategic orientation research (Lomberg et al., 2017). In doing so, we expect future research to be more cognizant of commonality analysis as a tool to compare the effects of multiple strategic orientations, and investigate higher-level dynamic capability-based phenomenon such as PLC.

The paper proceeds as follows. First, we develop our conceptual framework and research hypotheses. Then, we describe our sample, data collection and measurement 
approach. Next, we present our analysis, empirical findings, and robustness checks. Finally, we discuss our study findings and their meaningful implications for future research.

\section{Theory and research hypotheses}

\subsection{Individual effects of strategic orientations on firm performance}

The notion of a firm's strategic orientation has attracted attention of scholars from marketing, management, entrepreneurship, and other academic fields. Strategic orientation describes the organizational decision-making tendencies and principles of a company, which direct its activities and generate behavior, with the intent of achieving superior firm performance within the marketplace (Gatignon \& Xuereb, 1997; Hakala, 2011; Noble et al., 2002). Prior research distinguishes between several different types of strategic orientations, including market orientation (MO), entrepreneurial orientation (EO) and learning orientation (LO) (Hakala, 2011; Hult, Hurley, \& Knight, 2004). We now briefly examine each orientation in turn:

Market orientation. MO refers to strategic inclination and firm-level activities directed at the generation of superior value for customers. A market-oriented firm is one which "most effectively and efficiently creates the necessary behaviors for the creation of superior value for buyers and, thus, continuous superior performance for the business" (Narver \& Slater, 1990, p. 21). Prior research recognizes two main conceptualizations of MO (Gupta, Atav, \& Dutta, 2017): (a) relating to organization-wide generation and dissemination of market information and accompanying organizational responses (Kohli \& Jaworski, 1990), and (b) combining dimensions of customer orientation, competitor orientation, and interfunctional coordination (Narver \& Slater, 1990). Based on these characteristics, previous studies predominantly confirm a positive relationship between MO and business performance (Kirca et al., 2005; Lafferty, Hult, \& Thomas, 2001). Customers are more likely to be satisfied with products and services, provided by a market-oriented firm (Cooper, 2000), and 
increase their loyalty to the company. By gathering, disseminating, and employing customer and market information, MO enables firms to adjust their operations to target markets, anticipate and respond to customer needs, and build competitive advantage (Atuahene-Gima et al., 2005).

Entrepreneurial orientation. EO refers to organizations' strategic decision-making tendencies and behavioral actions, most commonly characterized in terms of innovativeness, proactiveness and risk-taking (Covin \& Lumpkin, 2011). Entrepreneurial firms engage in exploration of new products and services, and embrace forward-looking and somewhat risky courses of action (Rauch et al., 2009). Furthermore, EO describes a firm's tendency to experiment, generate new ideas, commercialize them into new products and services, and make substantial investments in research and development (Ardito, Petruzzelli, \& Albino, 2015; Lechner \& Gudmundsson, 2014; Lumpkin \& Dess, 1996; Vij \& Bedi, 2012). Overall, the adoption of EO, through the exhibition of innovative, proactive and risk-taking activities, can enable and help identify new ways of achieving firm performance (Caruana, Ewing, \& Ramaseshan, 2002; Gnizy et al., 2014; Rauch et al., 2009).

Learning orientation. LO is conceptualized as a "set of organizational values that influence the propensity of the firm to create and use knowledge" (Sinkula et al., 1997, p. 309). It represents the degree to which organizational learning and knowledge integration can occur within a firm, and beliefs and existing assumptions can be challenged. Widely applied components of LO include a commitment to learning, shared vision and open-mindedness (Sinkula et al., 1997). An additional dimension of intra-organizational knowledge sharing has also been examined (Calantone, Cavusgil, \& Zhao, 2002). Learning orientation is related to the firm's propensity to continuously question existing assumptions and beliefs about its business and environment, and the ability to deliver organizational change. Past research demonstrates that high-LO firms are better able to adapt their operational capabilities to the 
demands of the external environment when developing products and services (Lonial \& Carter, 2015; Wang, 2008). Learning from their environment and the opportunities which may exist, these firms are able to provide rapid solutions to different environmental challenges. Thus, a learning orientation helps firms create sustainable competitive advantages and enhance their performance (Baker \& Sinkula, 2009; Keith \& Stephen, 2006).

Several studies have examined market, entrepreneurial, and/or learning orientations as potentially complementary phenomena (Gnizy et al., 2014; Lonial \& Carter, 2015). In a few instances, the comparative strength of the orientations on firm performance has also been examined and produced mixed results. Whereas EO and MO were found to have a mostly positive association with performance (e.g., Hult et al., 2003), LO's performance effects seem to be less stable (e.g., Kropp et al., 2006; Laukkanen et al., 2013). In one notable example, Deutscher et al. (2016) observes that MO is the most relevant variable for explaining firm growth among high-technology firms. This study arguably provides an excellent example of the notion of orientation differentiation as discussed by Deshpandé, Grinstein, and Ofek (2012), which posits that with increasing competition, firms are likely to de-emphasize the strategic orientation their principal rivals pursue. A certain orientation, such as EO, may be less likely to provide a stable source of competitive advantage among such high-tech firms when it provides little differentiation (Gupta \& Gupta, 2015) and thus rather constitutes 'table stakes' or a necessary, but insufficient, condition for competitive advantage. In a similar vein, Kumar, Jones, Venkatesan, \& Leone (2011, p. 17) ask whether "as more firms in an industry become market oriented, does a firm's market orientation transform from being a success provider to being a failure preventer?". In response, we argue that that instead of relying on one single strategic orientation, a judicious fusion (or amalgamation) of various orientations may provide the strongest basis for increases in firm performance and growth. 
In general, among the three fundamental strategic orientations investigated in this study, we expect EO to provide the dominant explanation as to why some firms achieve above-average sales growth. While the intersection of these orientations may also considerably matter, we posit that among the strategic orientations investigated in this study, $\mathrm{EO}$, and the risky, pioneering innovation which it entails, is the principle orientation responsible for firms' sales growth. That is, bold, pioneering innovation is a prominent aspect of EO which enables organizational growth (Covin \& Miles, 1999). As such, EO may be viewed as a growth-focused orientation which engenders variance in firm performance and enables some firms to identify fruitful growth opportunities (Wiklund \& Shepherd, 2011). Indeed, prior research observes a strong and consistent effect of EO on growth (e.g. Brouthers, Nakos, \& Dimitratos, 2015; Casillas \& Moreno, 2010; Eggers, Kraus, Hughes, Laraway, \& Snycerski, 2013; Grande, Madsen, \& Borch, 2011; Shirokova, Bogatyreva, Beliaeva, \& Puffer, 2016; Soininen, Martikainen, Puumalainen, \& Kyläheiko, 2012).

All else being equal, we posit that risky, pioneering innovation within an organization's strategic orientation will explain more variance in sales growth than market or learning orientations which help firms understand, learn, and target their efforts successfully. While EO is a costly, risky orientation that may exhaust firm resources, with more productmarket launches, organizations have additional chances of being lucky, and striking a chord with customers in a new, and open competitive space that offers superior growth potential (Wiklund \& Shepherd, 2011). Thus, we argue that EO provides the 'high-risk, high-return' product-service innovation and new market entries necessary for firms to identify 'homeruns', along with 'base-hits' which keep firm sales growing (Covin \& Lumpkin, 2011). Market and learning orientations help firms grow sales by understanding and better learning about customers, competitors, and trends, however 'high-risk, high-return' pioneering 
innovation, is likely to produce stronger gains in sales growth. Thus, we assert that across orientations, EO is most directly responsible for firms' sales growth:

Hypothesis 1. Ceteris paribus, entrepreneurial orientation, rather than a market or learning orientation, provides the dominant explanation of variance in sales growth.

\subsection{Performance effects from the complementarity of strategic orientations}

Prior studies suggest that different combinations of orientations may enable firms to perform better as compared to when only a single orientation is emphasized in isolation (e.g., Boso et al., 2012; Farrell, 2000; Ho et al., 2016). These results align with the notion of complementarity which entails a "beneficial interplay of the elements of a system where the presence of one element increases the value of others" (Ennen \& Richter, 2010, p. 207), and a complementary set of resources can create additional value not captured by any one resource in isolation (Tanriverdi \& Venkatraman, 2005). Similarly, each strategic orientation captures different mechanisms for sustaining firm sales growth, and a combination of orientations may create more value compared to any individual orientation.

In explaining firm strategic orientation, scholars have predominantly utilized the resource-based view (RBV) to highlight strategic orientations as rare, valuable, inimitable and idiosyncratic organizational resources which may work in harmony to create superior firm performance and growth (Barney, 1991; Lonial \& Carter, 2015). An extension of RBV, the dynamic capabilities perspective conceptualizes strategic orientations in terms of firms' “capacity (1) to sense and shape opportunities and threats, (2) to seize opportunities, and (3) to maintain competitiveness through enhancing, combining, protecting, and, when necessary, reconfiguring the business enterprise's intangible and tangible assets" (Teece, 2007, p. 1319). In line with the RBV perspective, we recognize that strategic orientations such as EO, MO, and LO may work together to help firms recognize and seize opportunities. 
Many scholars (e.g., Baker \& Sinkula, 2009; Wiklund \& Shepherd, 2005) have argued that firms need to adopt an integrative approach to their strategic postures as relying on only one type of orientation may create opportunities with limited potential and durability. In this vein, many studies have focused on the interrelatedness and complementarity between EO and MO (Atuahene-Gima \& Ko, 2001; Bhuian et al., 2005; Slater \& Narver, 1995) as sources of competitive advantage and superior performance. According to Slater and Narver (1995), MO provides an effective foundation for organizational learning and generates performance when it is complemented by entrepreneurship. MO alone may inadvertently focus firms' efforts on current customers and competitors, thus, limiting attention to emerging markets and leading to adaptive learning within traditional boundaries. With the addition of EO, greater consideration is given to more imaginative and innovative product-markets. However, as innovative new product/market offerings carry a high risk of market failure, we believe that the adaptiveness of MO needs to be coupled with the generative nature of EO. Supporting this argument, Atuahene-Gima and Ko (2001) empirically observed that EO and MO can be integrated as an entrepreneurial marketing approach that drives new product performance.

Similarly, a synergistic relationship between MO and LO has been evidenced (i.e., Baker \& Sinkula, 1999) in which LO is viewed as the engine behind MO allowing to constantly examine the quality of information collection, interpretation and storage functions and the validity of the dominant logic that guides the entire organizational adaptive process. More broadly, the relationships between MO and EO, as well as MO and LO have been supported within a meta-analysis conducted by Grinstein (2008). The relationship between EO and LO has also been evidenced in the literature with LO representing an important, complementary strategic orientation for firms striving to achieve more from their entrepreneurial efforts (Gupta, Dutta, \& Chen, 2014; Liu, Luo, \& Shi, 2002). 
Bringing all three together within the same study, Deutscher et al. (2016) observe that a configuration of $\mathrm{EO}, \mathrm{MO}$, and $\mathrm{LO}$ drives organizational growth among high-tech firms. Lonial and Carter (2015) similarly observe all three, taken together, to have stronger effects with firm performance than when each orientation is considered in isolation. In this vein, the work of Li, Wei, and Liu (2010) observes that EO and MO are also complementary during the knowledge acquisition process that occurs during cross-border outsourcing. Thus, while all three strategic orientations are important for firm's growth and performance, it is their combination which arguably most significantly enhances firms' chances of growth and success (Deutscher et al., 2016; Gnizy et al., 2014; Lonial \& Carter, 2015).

An exploration-exploitation lens provides another perspective from which to consider the mutual criticality of all three strategic orientations. It has long been argued that EO captures an exploratory orientation emphasizing bold innovations (Wiklund \& Shepherd, 2011), whereas MO is focused more on exploitative possibilities derived from market gaps (Morgan \& Berthon, 2008). Moreover, we assert that LO serves as an 'organizational glue' that bonds EO and MO together by enabling firms to effectively process information, iterate upon their mistakes, and develop successful innovations (Sinkula et al., 1997). The work of Kraft and Bausch (2016) supports this proposed framework using a competing hypothesis research design, observing EO to be associated with explorative innovation, MO with exploitative innovation, and LO with both forms of innovation. Thus, a firm can scan markets and technologies, and spot opportunities for refining business models through its MO, explore ambitious possibilities for new entry and renewal through its EO, and continuously refresh organizational routines and perspectives using its LO.

To produce innovative new entries, firms increase EO (Lumpkin \& Dess, 1996); however, it is the complementary capabilities of MO, and LO that enable EO to maximize the promise of new product/service offerings. Absent MO, firms' EO efforts are less targeted, or 
firmly rooted in market demands. That is, technological myopia, or the building of products with entrepreneurs' ideas, rather than customers' needs, in mind is more likely when firms lack MO. Moreover, absent LO, entrepreneurial efforts will fail to achieve the iteration, or development cycles, necessary for new products to attain an effective fit with market demands. When EO is pursued, variance in firm performance increases (Wiklund \& Shepherd, 2011). Maximizing firm sales growth critically depends upon firms' ability to learn from their failed innovative efforts to solve customer problems and work towards achieving product-market fit and develop more scalable business models (Blank, 2013).

Ongoing discussion on the complementary effects of strategic orientations reinforces a need to provide a richer understanding of the co-variations manifest between orientations, and their shared associations with business performance. To this end, we examine the complementary effect of MO, EO and LO on performance, and hypothesize that:

Hypothesis 2. When the variance within the relationships between (a) MO, (b) EO and (c) LO and firm sales growth is decomposed and compared, the shared variance at the intersection of all three strategic orientations matters more than their individual effects.

\subsection{Proactive learning culture as a strategic orientation synthesis}

The complementary nature of EO, MO, and LO has been widely discussed in the literature from a bi-variate standpoint (e.g., Atuahene-Gima \& Ko, 2001; Boso, Cadogan, \& Story, 2013; Boso, Story, \& Cadogan, 2013) as well as based on the simultaneous consideration of multiple orientations (Hakala, 2011). Proponents of the complementarity perspective explain how value emerges from a combination of strategic orientations as opposed to finding the right sequences or alternatives of orientations (see Hakala, 2011). Past research has typically viewed the combination of $\mathrm{EO}, \mathrm{MO}$, and $\mathrm{LO}$ as a higher-order construct, and given this concept various labels such as 'strategic orientation' (e.g., Zhou, Yim, \& Tse, 2005), 'positional advantage' (e.g., Lonial \& Carter, 2015), or 'culture of competitiveness' (Hult et 
al., 2007). More recently, Gnizy et al. (2014) refer to the intersection of these strategic orientations as a 'proactive learning culture', which drives foreign market launch success. In effect, pairing LO with MO and EO will lead to enhanced learning about new potential product-market opportunities. Moreover, building upon Hult and Ketchen (2001), Lonial and Carter (2015) view the intersection of these strategic orientations as creating a "positional advantage' for the firm within the marketplace. That is, exhibiting $\mathrm{EO}$ and $\mathrm{MO}$, combined with LO is likely to help the firm deploy unique and difficult to imitate skills and resources while working towards firm performance and growth. In this vein, Deutscher et al. (2016) observes partial support for the notion that highest firm performance is achieved when EO, MO, and LO are all at high levels.

Building upon prior research and following Gnizy et al. (2014), we examine EO, MO, and LO as essential indicators of a firms' strategic priorities and how they may reflect a higher order construct - proactive learning culture (PLC). We support the notion that PLC be viewed as a dynamic capability "through which SMEs can configure resources and capabilities" (Gnizy et al., 2014, p. 482), which may increase firm performance. To exhibit a proactive learning culture, firms must understand/monitor customers, competitors, develop and proactively introduce innovations, and be able to question assumptions and learn (that is, develop open-mindedness, a commitment to learning, and shared vision). PLC melds building and launching new product-market offerings (EO), with understanding customer needs and competitor gaps (MO), and a commitment to learning and open-mindedness (LO). Building upon past research conceptualizing PLC, we hypothesize and test:

Hypothesis 3a. As fundamental organizational strategic orientations, entrepreneurial, market, and learning orientations represent critical components and indicators that contribute to a higher-order, proactive learning culture within organizations.

Hypothesis 3b. Proactive learning culture positively relates to firm sales growth. 


\section{Method}

\subsection{Sampling}

To test our hypotheses, survey data were collected in Finland and Russia during 2013-2014. Strong historical, geographical, political, and economic ties connect Finland and Russia with each other. To illustrate, the two countries share a common border and a long history of relationships as well as strong trading partnership. Companies, constituting the population for the research, were privately owned Finnish and Russian firms, operating in different industries. To reduce potential cross-country construct invariance, the method of translation and back translation of the questionnaire was used (Brislin, 1970), and pilot testing was undertaken.

The population of Finnish and Russian firms meeting the selection criteria was retrieved from the Amadeus database ${ }^{1}$ and SPARK-Interfax database ${ }^{2}$ respectively. From these populations, a sample of 8,000 Finnish and 12,000 Russian companies were randomly selected, and a standardized questionnaire was distributed to the key respondents of the whole sample using the online survey and analysis tool Webropol 2.0. Data were collected separately in two countries. We distributed the standardized questionnaire to companies' founders and/or CEOs, as these respondents are most knowledgeable about firm strategy (Calantone et al., 2002; Deutscher et al., 2016). Since the number of emails that reached the respondents may have been substantially reduced due to potential technical issues, e-mail protection tools or human factors (Franke, Hippel, \& Schreier, 2006; Tse, 1998), response rate was calculated by accounting only for respondents who actually viewed the questionnaire. The number of these respondents was estimated by Webropol as being 535 and

\footnotetext{
1 Amadeus (Bureau van Dijk) is a database of financial and business information on around 21 million European companies. It contains financial statement data as well as basic company information, including sectoral activities, corporate structures, market research, and business and company-related news.

${ }^{2}$ The SPARK-Interfax (System of Professional Analysis of Markets and Companies) database covers 12 million Russian, Ukrainian, and Kazakh companies, accumulates information from all possible official sources and enables comparative analysis of data on companies, markets, industries and regions as well as ranking by more than 1000 business and financial indicators.
} 
1,340 Finnish and Russian respondents, respectively. Overall, we collected 117 Finnish and 106 Russian questionnaires with the effective response rate of $21.9 \%$ in Finland and $7.9 \%$ in Russia. Other studies have also acknowledged the generally low response rate among Russian firms which is likely caused by the reluctance of managers to disclose their activities and provide requested information (Shirokova et al., 2016; Shirokova, Vega, \& Knatko, 2015).

To address concerns about potential non-response bias, the samples were split in two groups based on the dates the completed surveys were received. The early-wave groups consisted of 58 and 52 respondents in Finland and Russia respectively, while the rest of the samples represented late-wave groups. In both samples, t-tests yielded no significant differences between the two groups for all variables of interest. Further, the Amadeus database allowed comparing nonresponding Finnish firms $(n=7,883)$ with those who responded $(\mathrm{n}=117)$. Using t-test for firm size and chi-square test for industry, no significant differences between the group of respondents and non-respondents were found, demonstrating that nonresponse bias does not represent a significant problem in the study. After data cleaning, the final pooled dataset of Finnish and Russian companies was 221 firms.

Firms in our sample are quite evenly distributed regarding the country of origin: $52 \%$ Finnish and $48 \%$ Russian. By size, the majority of firms are small with an average of 53 employees, ranged between 1 and 500 employees. The firms have been operating between 2 and 108 years since their foundation, and, on average, for 14.6 years. The majority of firms operate in a service sector $(46.15 \%)$, and a number of firms operating in production and occupied with informational and intellectual activities are distributed equally $(26.24 \%$ and $27.60 \%$ accordingly).

\subsection{Measures}

\subsubsection{Dependent variable}


We adopt a financial indicator for sales growth rate which has been widely used in the management and marketing literatures to measure firm performance (Delmar, Davidsson, \& Gartner, 2003). Sales growth was operationalized as the percentage change in firms' sales from 2010 to 2012. This measure was included in the questionnaire as publicly available performance indicators are less accessible for small firms compared to larger organizations. The measure was then checked using the information from the official databases (SPARK Interfax, Amadeus), giving preference to objective data where possible.

\subsubsection{Independent variables}

In measuring firm's strategic orientations, the current study relies on the established scales. All the questions in the survey were related to firms' activities in 2012. Following Narver and Slater (1990), we operationalized market orientation as a three-dimensional construct, comprising customer orientation, competitor orientation and inter-functional coordination. A fifteen-item scale adapted from Narver and Slater (1990) was used to measure firm-level MO. The items were measured on a five-point Likert scale and included six items for assessment of customer orientation, four items for measurement of competitor orientation and five items for assessment of inter-functional coordination.

The operationalization of entrepreneurial orientation was based on the work of Covin and Slevin (1989) and captured the dimensions of innovativeness, proactiveness and risktaking (Covin \& Lumpkin, 2011). The nine-item seven-point scale, which comprised of three items for each dimension, was employed to measure firm-level EO.

Learning orientation was operationalized with three dimensions of commitment to learning, shared vision and open-mindedness, following Sinkula et al. (1997). From the existing literature, the eleven-item scale was used to measure firm-level LO. The scale comprises four items for commitment to learning and shared vision, and three items for openmindedness, measured on a seven-point Likert scale. 
Table 1 describes the specific items used for construct measurement and their respective factor loadings.

Insert Table 1 about here

Control variables. The level of strategic orientations and firm sales growth outcomes might also be contingent on firm age, size, and type of industry, which were used as control variables in the study. Firm age was estimated by the number of years since the firm was started. Firm size was operationalized as the total number of employees in 2012. In order to respond to the assumption of distribution normality, a natural logarithm transformation of these variables was taken. To control for industry, three dummy variables were created, reflecting companies' activities in one of the following sectors of economy: production, services, or intellectual and informational activities.

To address concerns about common method bias, Harman's single-factor test was applied. Principal component factor analysis with all variables yielded six factors with eigenvalues greater than 1 , with the variance explained by the first factor accounting for less than $50 \%$ of the total variance, indicating that common method variance is not a substantive concern in this study. Additionally, the complicated specifications of the models, which includes unique and shared effects of the orientations, are unlikely to be perceived by respondents (Chang, van Witteloostuijn, \& Eden, 2010).

\section{Data analysis and results}

\subsection{Reliability and validity of the constructs}

We conducted unpooled data analysis at the country level to ensure that the measures work satisfactorily in each country, and then performed pooled data analysis with "decultured" (standardized in each county's sample) data to determine the common relationships across 
countries. This two-step procedure provides a rigorous test of the research model in a multicountry setting (Engelen, Gupta, Strenger, \& Brettel, 2015).

For each country separately, confirmatory factor analysis (CFA) using maximum likelihood estimation was conducted on each of the latent constructs of MO, EO, and LO to examine the constructs' unidimensionality, reliability and validity. Because the sample size for each country is not sufficient enough to assess complex models, we analyzed the scales separately in order to mitigate risk of violating minimum sample size to parameter ratios. In the first measurement model, we examined the MO construct and its dimensions of customer orientation, competitor orientation and inter-functional coordination. The second measurement model contained the three dimensions of EO: innovativeness, proactiveness and risk-taking. In the third model, we assessed LO dimensions of commitment to learning, shared vision and open-mindedness. CFA helps to identify problematic items in the constructs, and, based on the factor loadings, fit statistics, and modification indices, several items which were not tapping a single underlying construct were eliminated (Gerbing \& Anderson, 1988). Model re-specification helps adjust the constructs to the data, improving overall data fit. Given the sample size, all measurement models exhibited adequate fit to the data (Finland/Russia: MO: $\chi^{2} / \mathrm{df}=2.02 / 1.83 ; \mathrm{GFI}=0.90 / 0.91 ; \mathrm{CFI}=0.92 / 0.92 ; \mathrm{RMSEA}$ $=0.09 / 0.09 ; \mathrm{EO}: \chi^{2} / \mathrm{df}=0.79 / 1.70 ; \mathrm{GFI}=0.97 / 0.93 ; \mathrm{CFI}=1.00 / 0.95 ; \mathrm{RMSEA}=0.00 /$ $\left.0.08 ; \mathrm{LO}: \chi^{2} / \mathrm{df}=1.81 / 1.01 ; \mathrm{GFI}=0.92 / 0.95 ; \mathrm{CFI}=0.97 / 1.00 ; \mathrm{RMSEA}=0.08 / 0.01\right)$ and all items loaded on singular underlying latent variables respectively, demonstrating unidimensional measurements and convergent validity.

We checked latent variables for measurement invariance using multi-group CFA analysis to indicate that the same constructs were measured in both countries, and the measure was interpreted in a conceptually similar manner by the respondents (Vandenberg \& Lance, 2000). The results have confirmed configural invariance between two country groups 
$\left(\chi^{2} / \mathrm{df}=1.72 ; \mathrm{GFI}=0.93 ; \mathrm{CFI}=0.95 ;\right.$ RMSEA $\left.=0.06\right)$, showing that respondents conceptualize the constructs in the same way, and the data collected in each country represent the same number of factors with the same items associated with each factor. Further, a chisquare difference test between the baseline model and the model with all factor loadings constrained to be the same across groups established metric invariance, indicating that the country groups are equivalent with regard to factor structure, that is, the relationships between specific scale items and the construct are the same across the groups. Additionally, to complement the chi-square difference test, CFI difference between the two models was calculated following Cheung and Rensvold (2002). An estimated decrease of 0.003 in CFI does not exceed the proposed threshold value of 0.01 , further confirming the measurement invariance and suggesting that combining data from the two countries is acceptable.

As the current research does not focus on comparative analysis and establishing differences between the countries, but rather on establishing strong effects that are generalizable across different country contexts, we removed national bias by standardizing data separately in each country before pooling it and performing the analyses. Data standardization helps 'deculture' the data (Song, Kawakami, \& Stringfellow, 2010), so that the true correlation between the variables is not affected by country-specific characteristics. It also helps to increase confidence in the robustness of hypothesized effects and determine whether there is a common core of relationships across the countries (Engelen et al., 2015; Song et al., 2010). In the following analyses, we accessed the robustness and cross-national applicability of the measurement models, performed a commonality analysis (Lomberg et al., 2017; Mood, 1971; Seibold \& McPhee, 1979) and applied structural equation modelling (SEM) to test our hypotheses using the pooled data set.

Similar to the separate country analysis, CFA was performed to evaluate the scales of each strategic orientation. The scales were analyzed in sub-models, and then the whole 
measurement model with all strategic orientations included was examined (Boso et al., 2013b). To estimate the goodness of fit of the models, we used (a) chi-square goodness-of-fit statistic, (b) goodness-of-fit index (GFI), (c) comparative fit index (CFI), (d) standardized root mean residual (SRMR), and (e) root mean-square error of approximation (RMSEA) (summarized in Table 2). We considered GFI and CFI above the values of 0.95 along with SRMR and RMSEA below 0.08 as indicators of a good model fit (Hu \& Bentler, 1999).

Insert Table 2 about here

Chi-square values for MO, LO and full measurement models were significant $(p<$ 0.05), and all other fit indices were within the acceptable cut-off ranges. Specifically, indices for the full measurement model were satisfactory $(\mathrm{GFI}=0.96, \mathrm{CFI}=0.97, \mathrm{SRMR}=0.05$ and RMSEA $=0.06, \mathrm{~ns}$.$) , and, therefore, demonstrate the applicability of the constructs' structure$ to the data (Anderson \& Gerbing, 1992; Byrne, 2009). Again, all items loaded on singular underlying constructs respectively, implying that there were no departures from unidimensionality. Table 1 contains the final list of items, standardized factor loadings and the results of reliability and validity tests. The positive and significant loadings confirm convergent validity of the measures. Results also show acceptable levels of average variance extracted (AVE) and composite reliability (CR) of the variables.

Finally, the resulting values of multiple-item variables were calculated as an average score on all the items. Table 3 contains descriptive statistics and correlations between the studied constructs. The largest correlation coefficient is 0.59 (between MO and LO). The test for multicollinearity in the model has shown that all variance inflation factors (VIFs) are below 3 with an average of 1.46 (VIF $=1.77$ for MO; 1.65 for LO; 1.31 for EO), which assuages possible concerns of multicollinearity and implies that the model with all variables included can be estimated (O’Brien, 2007). 


\subsection{Commonality analysis}

To test hypotheses 1 and 2, commonality analysis was performed to decompose the total variance in firm sales growth explained by three strategic orientations (Lomberg et al., 2017; Mood, 1971; Seibold \& McPhee, 1979). Commonality analysis compares variance explained by the models with different subsets of independent variables and is particularly relevant when those are substantially correlated. This characteristic makes it appropriate for analyzing strategic orientations. Commonality analysis allows to uncover the structure of explanatory power of the PLC dimensions' for sales growth by assessing the parts of variance attributed to unique effects (variations only in $\mathrm{EO}, \mathrm{MO}$, or $\mathrm{LO}$ ), bilaterally shared effects (covariations between any pair of strategic orientations), and commonly shared effects (covariation between all strategic orientations). The sum of unique, bilaterally and commonly shared effects of EO, MO, and LO represents their total effect on firm sales growth. ${ }^{3}$

By applying the commonality analysis to strategic orientations, we assess the extent to which the contributions of EO, MO and LO are unique and shared between any of the pairs of strategic orientations and the combination of all three orientations, while controlling for firm age, size and industry effects. The results of variance decomposition are presented in Table 4 and graphically illustrated in Figure 1.

Insert Table 4 and Figure 1 about here

\footnotetext{
${ }^{3}$ Commonality analysis is an approach to partition variance in the dependent variable $\left(\mathrm{R}^{2}\right)$ and decompose it into the effect uniquely and commonly explained by the predictor variables. Compared to multiple regression, which involves a sequential analysis of the effects on a predicted variable, in a commonality analysis, performance effects from predictors are estimated simultaneously. Moreover, shared effects are different from interaction effects in that an interaction effect indicates that the strength of the relationship between two variables depends on the level of the third variable, whereas a shared effect indicates that a change in one variable only affects another variable if it is associated with a change in the third variable (independent of its level). Additionally, for an interaction effect to be observed, the interacting variables do not need to be correlated, while for a shared effect, they must be correlated and conjointly affect firm performance (Lomberg et al., 2017, p. 976). Compared to SEM, which allows to estimate shared (common) variance between the variables as indicators of a higher-order construct, commonality analysis identifies other types of variance (bilaterally shared and unique) providing a more fine-grained approach.
} 
The total effect of all strategic orientations after accounting for the effects of control variables is statistically significant (Line 8: $0.037, p<0.05$ ). This result indicates that the total effect of EO, MO, and LO explains a significant amount of performance variation as an increment in explained variance in sales growth. Among the individual effects of strategic orientations, only EO shows a significant unique effect (Line 1: $0.016, p<0.10$ ) on firm sales growth which accounts for $42 \%$ of the explained variance. The unique effects of MO and LO (Lines 2 and 3) do not explain sales growth in a statistically significant way, indicating that most of their explanatory power is shared with EO. Therefore, when comparing the effects of three strategic orientations on sales growth, only entrepreneurial, as opposed to market or learning orientation, explains the dominant amount of variance, providing support for hypothesis 1 .

The significance levels for shared effects are based on largest bias-corrected and accelerated bootstrapped confidence interval not including zero (Lomberg et al., 2017). The largest part of the shared effects is a statistically significant commonly shared effect between EO, MO, and LO (Line 7: 0.010, $p<0.05$ ), which explains $26 \%$ of variance in sales growth. Interestingly, the unique EO effect is larger (Line 1: 0.016, $p<0.10$ ) than the commonly shared effect attributed to covariation of all three strategic orientations and smaller than the sum of their shared effects (Lines 4-7: $0.005+0.001+0.003+0.010=0.019$ ). The latter explain about half of the total effect (Line 8: 0.037) from the three strategic orientations and emphasize the importance of synthesizing EO, MO, and LO. Thus, the results do not support hypothesis 2 that the shared variance at the intersection of all three strategic orientations matters more compared to their individual effects.

\subsection{Structural equation modeling}

To test hypotheses $3 \mathrm{a}$ and $3 \mathrm{~b}$, we utilized structural equation modeling and estimated the effect of PLC as a three-dimensional higher-order construct on firm sales growth. First, we 
estimated the individual effects of MO, EO, and LO on sales growth. The model has demonstrated a satisfactory fit to the data $\left(\chi^{2} / \mathrm{df}=2.27, p=0.01 ; \mathrm{GFI}=0.97 ; \mathrm{CFI}=0.95\right.$; $\mathrm{SRMR}=0.06 ; \mathrm{RMSEA}=0.08, p=0.11)$. Similar to results of the commonality analysis, $\mathrm{EO}$ is significantly and positively related to firm sales growth $(b=0.14, p<0.05)$, while MO and LO are not directly associated with superior sales growth, confirming that in our sample it is driven primarily by EO rather than MO or LO.

In the complementarity model, MO, EO, and LO are conceptualized and tested as indicators of a higher-order PLC construct. A structural model allows the estimation of a firm-level common factor ${ }^{4}$ underlying learning, market, and entrepreneurship behaviors (George, 2011). In this case, PLC is represented by the extent to which the sub-dimensions covary, such that only a change in all three dimensions would represent a change in PLC. We therefore can (a) assess the validity of the PLC construct and (b) estimate the amount of variance in performance resulting from a change in the underlying first-order constructs. SEM results are presented in Table 5 and graphically illustrated in Figure 2.

\section{Insert Table 5 and Figure 2 about here}

The model goodness-of-fit indices were within the acceptable cut-off ranges $\left(\chi^{2} / \mathrm{df}=\right.$ 2.13, $p=0.01 ; \mathrm{GFI}=0.97 ; \mathrm{CFI}=0.95 ; \mathrm{SRMR}=0.06 ; \mathrm{RMSEA}=0.07, p=0.14)$. The results shown that all three strategic orientations significantly load on the higher-order construct $(\mathrm{PLC} \rightarrow \mathrm{MO}: b=0.58 ; p<0.001 ; \mathrm{PLC} \rightarrow \mathrm{EO}: b=0.75 ; p<0.001 ; \mathrm{PLC} \rightarrow \mathrm{LO}: b=0.40 ; p$ $<0.001$ ), providing support for hypothesis 3a that EO, MO, and LO represent fundamental components of firms' PLC. We tested for the presence of the second-order factor complementarity model by calculating a target coefficient (T) (Marsh \& Hocevar, 1985), which is the ratio of the chi-square of the first-order (individual effects) factor model to the chi-square of the second-order factor model. The $T$ target coefficient equaled 0.99 justifying

\footnotetext{
${ }^{4}$ Note that in SEM analysis only the commonly shared variance is attributed to the multidimensional construct, whereas the other types of variance (bilaterally shared and unique) are considered as part of the error variance (Law \& Wong, 1999).
} 
the existence of the second-order factor model. Further, the effect of PLC on firm sales growth was found to be positive and significant $(b=0.23, p<0.01)$, supporting hypothesis 3b. This result demonstrates that firms with multiple strategic orientations exhibit higher levels of firm sales growth.

\subsection{Post-hoc analysis}

We conducted several analyses to examine the robustness of our findings. First, we included 'country' as a control variable and reran the models. The results indicate that the sign and significance of predictor variables remain unchanged meaning that performance in our sample is not driven by the country effects.

Second, we applied a different dependent variable - profit growth, measured as the percentage change in firm profits from 2010 to 2012. As expected, profit and sales growth were highly correlated $(0.73, p<0.01)$ and therefore included in our calculations separately. Specifically, we used the same models to perform commonality analysis and SEM for profit growth. When decomposing variance for profit growth, most of it is explained by the unique effect of EO $(0.023, p<0.05 ; 27 \%)$ and commonly shared effect of all strategic orientations $(0.023, p<0.05 ; 27 \%)$. Besides this, the results have also shown that unique LO $(0.017, p<$ $0.10 ; 20 \%)$ and bilaterally shared EO \& LO $(0.007, p<0.05 ; 8 \%)$ effects contribute to the variance in profit growth, but to a smaller extent. More than half of the variance is attributed to shared effects, confirming the relevance of synthesizing EO, MO, and LO. The SEM model of complementary effects of strategic orientations confirmed the positive effect of firm's PLC $(\mathrm{PLC} \rightarrow \mathrm{MO}: \mathrm{b}=0.59, p<0.001 ; \mathrm{PLC} \rightarrow \mathrm{EO}: \mathrm{b}=0.64, p<0.001 ; \mathrm{PLC} \rightarrow \mathrm{LO}:$ $\mathrm{b}=0.49, p<0.001)$ on profit growth $(b=0.37, p<0.001)$, providing support for combining EO, MO, and LO into a collective catchall that captures firm proactive learning culture.

Third, we compared the data fit of complementarity model with eight alternative SEM models: individual effects models with and without covariates between EO, MO and LO, and 
six additional reduced models, in which each of the three orientations and all pairs of the orientations were assessed as indicators of PLC (Table 6).

\section{Insert Table 6 about here}

All reduced models - except models 1, 4 and 6-exhibit acceptable fit characteristics, showing general consistency with prior research on positive performance effects of these orientations. Individual effects model with covariates between orientations fits the data in a similar manner as the complementarity model but has less explanatory power. However, when covariates are removed, the model exhibits poor fit statistics and is inferior to the complementarity model. This finding additionally supports the hypothesized model and the results of the commonality analysis which indicate that the three orientations commonly share a significant portion of variance. Thereby, we provide a more comprehensive understanding of factors impacting performance.

\section{Discussion and implications}

Several notable strategic orientations have taken center stage within recent research exploring management and marketing (Hakala, 2011). This study offers a systematic decomposition and comparison of the variance attributed to three fundamental firm strategic orientations, $\mathrm{EO}, \mathrm{MO}$, and LO, on a key indicator of firm performance, organizations' sales growth. Moreover, this study advances our understanding regarding the shared variance of EO, MO, and LO as capturing a firm's proactive learning culture. As such, this study has several notable implications.

First, using the technique of commonality analysis (Lomberg et al., 2017), our investigation of the individual unique effects of the three fundamental firm orientations reveals that firm performance, measured as sales growth, is overwhelmingly driven by EO within our cross-national random sample of 221 firms from Finland and Russia. Firms with 
high levels of EO pursue bolder, more radical innovation, accept greater risk and proactively operate in the marketplace (Covin \& Slevin, 1989: Covin \& Lumpkin, 2011). Therefore, our results suggest that it is $\mathrm{EO}$, more so than $\mathrm{MO}$ or $\mathrm{LO}$, that is responsible for gains in firm sales growth, a finding which runs contrary to studies suggesting stronger relationships between MO and sales growth (i.e., Deutscher et al., 2016). Thus, at least for firms in our sample, channeling resources toward EO, and the bolder, more exploratory and radical innovations bear the highest potential for sales growth.

We further observe that while EO is positively associated with firm sales growth, MO- and LO-sales growth relationships did not reach significance. In our sample, MO's performance effect is not statistically significant, suggesting that it may have become a cost of competing rather than a source of advantage (Kumar et al., 2011). Concerning LO, the existing literature contains evidence that its effect on firm performance may be weak and context dependent (Laukkanen et al., 2013), and LO primarily drives non-financial rather than financial performance (Yilmaz, Alpkan, \& Ergun, 2005).

Second, contrary to the observation of Gnizy et al. (2014) that PLC, constituting of $\mathrm{EO}, \mathrm{MO}$ and LO, influences performance stronger than any subset of its components, our results fail to provide support for hypothesis 2, that complementary - commonly shared effects of $\mathrm{EO}, \mathrm{MO}$, and $\mathrm{LO}$ - explain significantly more variance in firm sales growth than the unique, or bi-laterally shared effects in isolation. Although the commonly shared variance between $\mathrm{EO}, \mathrm{MO}$, and $\mathrm{LO}$ accounts for a sizeable percentage, e.g., more than a quarter of the variance in the relationship with firm performance, the unique explanatory variance attributable to EO still overshadows this effect. While past SEM models examining and comparing model fit have advanced our understanding of the important intersection of EO, MO, and LO, they have unfortunately fallen short of illuminating such important nuances. 
Moreover, complementarity strategies have previously been viewed as separate pieces of a puzzle that complete each other or as mutually reinforcing practices that create synergistic performance effects (Tanriverdi \& Lee, 2008, p. 384). Our study demonstrates that these are not mutually exclusive views. Indeed, EO, MO, and LO contribute both uniquely (independently from each other) and jointly (as shared effects) to firm performance and specifically, to sales growth. Overall, while the shared variance among EO, LO, and MO appears to clearly matter as a driver of firm performance, EO is manifest as the dominant explanation of variance within our cross-national random sample.

Further, we acknowledge that it is reasonable to expect context dependencey, for instance, when restricting the sample to SMEs (Lonial \& Carter, 2015) or high-tech firms (Deutscher et al., 2016), which may shape which strategic orientations contribute most significantly to key aspects of firm performance such as sales growth as investigated in this study. For instance, among high-tech firms where EO is more commonplace, MO may be a stronger differentiating factor (Deshpandé et al., 2012). Recognizing that past research has at times documented MO to have a stronger effect on firm performance than either EO or LO, our findings suggest that (a) these three strategic orientations collectively represent essential indicators of a firms higher order dynamic capability, labeled PLC (in line with Gnizy et al., 2014) and (b) the dominant explanation of variance between EO, MO, and LO appears to be context dependent.

Thus, while being high on all dimensions often affords organizations a greater positional advantage (Lonial \& Carter, 2015), in certain contexts different levels and combinations of the orientations may be warranted. This perspecitve of PLC is in line with Miller's (2011, p. 874) observation that strategic orientation phenomena may vary based on context, and thus it is wise to consider strategic orientations such as PLC, from a perspective that is "broad enough to capture different sorts of processes in different contexts." The heart 
of a firm's PLC lies at the intersection of these three strategic orientations, although their relative weighting and influence is context dependent. Thus, it is important to gain insight into which strategic orientations contribute most significantly to firm performance within particular contexts, and to continue to investigate their combination and mutual pursuit as a means to explain firm performance and growth within a wide variety of contexts (Deutscher et al., 2016; Gnizy et al., 2014; Lonial \& Carter, 2015).

Recognizing EO, MO, and LO as essential indicators of a higher order dynamic capability helps advance the conversation on strategic orientations. To this end, future studies should strive to examine all three orientations as fundamental pieces of a puzzle that offer a holistic picture of firms' growth posture and strategy. This is not to suggest that research avoid focusing specifically on the effects of EO, MO, or LO in isolation. Undoubtedly, important nuances specifically associated with entrepreneurial-, market-, or learning-oriented organizations still demand investigation. Nonetheless, it is important to recognize that each of these elements is part of PLC that describes firms' competitive efforts. Thus, examining EO without MO or LO presents a limited, albeit focused perspective that is principally concerned with exploration, and firms' bold, pioneering innovation efforts, without taking into account how adept the firm is at learning or marketing.

A practical implication of this research is that managers prioritizing achieving sales growth should adopt an innovative, EO-related strategic posture, which, in our sample, explains more than 40 percent of the variance in sales growth. Nonetheless, divergence from past findings suggests the importance of future research into whether different elements of a firm's proactive learning culture matter more in specific industries/environments. The answer to the question, which orientation matters the most, is arguably it depends, though the combination of EO, MO, and LO is observed to play an important role in firms' growth. 


\section{Limitations and additional areas for further research}

As with any study, this research has certain limitations and offers areas for future research. First, while data collection at a single point in time is a common practice within research on firms' strategic orientations, it does limit claims of causality. Further, we used a growthbased performance measure as a dependent variable, and so the efficacious elements of a firm's PLC may change based upon the nature of the dependent variable. We encourage further examination of other measures of firm performance and when data permitting, use of a longitudinal design to establish the effects from strategic orientation in the long-run and assess possible evolutionary changes in the relationships between the three orientations. For instance, perhaps if survival (rather than growth) is examined, we might observe a stronger shared-effect of EO, MO, and LO. That is, while EO drives firm growth, there is potentially a survival bias involved, so that EO is greater, among surviving firms, at explaining firm growth. However, when survival is considered, MO and LO may play a larger role in helping firms survive due to more thoroughly considered market alignment.

This study is also based on a sample collected from Finland and Russia, which, despite their geographical, historical, economic and political ties, are different nations. Although we performed a 'decultured' pooled data analysis (Engelen et al., 2015), which helped to eliminate national bias, replication studies using different samples will further improve the external validity of the findings. Future research exploring PLC may verify the results obtained in this study in other countries and more fully investigate the link between these strategic orientations and performance in different settings.

Our finding about EO's greater potency compared to the other two strategic orientations may also be a function of the social and institutional context in which our research is conducted. It is possible that specific aspects of Finnish and Russian society may align to make it more conducive for firms to benefit from their EO as compared to MO and 
LO. The extent to which our findings generalize to other countries is an empirical issue, and future research would do well to examine the relative efficacy of the three strategic orientations in other national, institutional, or socio-cultural contexts.

In terms of future model building, our research suggests that it is beneficial to examine configurations of these strategic orientations to determine which aspects of proactive learning culture are most relevant and pronounced within various industry/environmental contexts. As most firms in our sample are small, relatively young and dynamic, future research should explore the robustness of our findings in older, larger, and less dynamic environments. Further, when investigating aspects of PLC such as EO, MO, or LO in isolation, it may be helpful to compare and control for the other elements of PLC to increase confidence in the strength of study findings. Further, it may be wise to reconsider past models examining mediating effects among $\mathrm{EO}, \mathrm{MO}$, and $\mathrm{LO}$ and firm performance as potentially reciprocal. That is, for instance, $\mathrm{MO} \rightarrow \mathrm{LO} \rightarrow$ firm performance and $\mathrm{LO} \rightarrow \mathrm{MO} \rightarrow$ firm performance may both be significant as these central aspects and elements of a broader PLC are highly correlated. LO likely drives MO, and vice versa. While there have been numerous calls for mediation research (Wales, 2016), such studies are likely to be most beneficial when examining factors outside of strategic orientations themselves as mediating influences on firm performance.

Future research exploring multiple strategic orientations may also examine the role of different aspects of the external environment, including environmental dynamism, heterogeneity, density, and institutional and cultural characteristics, to better explain when individual or complementary strategic orientations improve firm performance (Hult et al., 2004; Zhou et al., 2005). Internal factors are also relevant considerations. For instance, Slater and Narver (2000) argue that MO is primarily concerned with learning from contacts with customers and competitors, whereas EO implies learning from experimentation. 
Organizational structure and/or leadership style might also shed additional light on these relationships. In general, it is our hope that this study sparks additional research exploring the intersection of $\mathrm{EO}, \mathrm{MO}$, and $\mathrm{LO}$, and the concept of proactive learning culture.

Apart from strategic orientations, commonality analysis can also be applied to other concepts in management, marketing, and entrepreneurship research, such as exploration and exploitation, competition and co-operation, effectuation and causation, incremental and radical innovation, opportunity discovery and creation, to help answer the extent to which variation in key aspects of firm performance and growth are explained by unique and shared effects. This methodology offers a useful approach to examine such constructs in different competitive scenarios and environmental settings, and promotes a new lens for strategic orientation studies.

\section{Conclusion}

Three major strategic orientations have attracted considerable research interest - EO, MO, and LO. We observe that when combined, these fundamental organizational strategic orientations give rise to a higher order construct labeled PLC. Commonality analysis further reveals that firm sales growth is impacted more by EO, than MO or LO. Specifically, although the shared effects at the intersection of all three strategic orientations, i.e., PLC, exceeds the explanation of bilaterally shared effects, the unique effect of EO on firm performance is even stronger. It is our hope that this research will inspire future investigations that examine and compare firm strategic orientations.

\section{References}

Anderson, J. C., \& Gerbing, D. W. (1992). Assumptions and comparative strengths of the two step approach: Comment on Fornell and Yi. Sociological Methods \& Research, 20(3), 321-333. https://doi.org/10.1177/0049124192020003002 
Ardito, L., Petruzzelli , A. M., \& Albino, V. (2015). From technological inventions to new products: A systematic review and research agenda of the main enabling factors. European Management Review, 12(3), 113-147. https://doi.org/10.1111/emre.12047

Atuahene-Gima, K., \& Ko, A. (2001). An empirical investigation of the effect of market orientation and entrepreneurship orientation alignment on product innovation. Organization Science, 12(1), 54-74. https://doi.org/10.1287/orsc.12.1.54.10121

Atuahene-Gima, K., Slater, S. F., \& Olson, E. M. (2005). The contingent value of responsive and proactive market orientations for new product program performance. Journal of Product Innovation Management, 22(6), 464-482. https://doi.org/10.1111/j.1540$\underline{5885.2005 .00144 . x}$

Baker, W. E., \& Sinkula, J. M. (1999). The synergistic effect of market orientation and learning orientation on organizational performance. Journal of the Academy of Marketing Science, 27(4), 411-427. https://doi.org/10.1177/0092070399274002

Baker, W. E., \& Sinkula, J. M. (2009). The complementary effects of market orientation and entrepreneurial orientation on profitability in small businesses. Journal of Small Business Management, 47(4), 443-464. https://doi.org/10.1111/j.1540-627X.2009.00278.X

Barney, J. (1991). Firm resources and sustained competitive advantage. Journal of Management, 17(1), 99-120. https://doi.org/10.1177/014920639101700108

Bhuian, S. N., Menguc, B., \& Bell, S. J. (2005). Just entrepreneurial enough: The moderating effect of entrepreneurship on the relationship between market orientation and performance. Journal of Business Research, 58(1), 9-17. https://doi.org/10.1016/S0148$\underline{2963(03) 00074-2}$

Blank, S. (2013). Why the lean startup changes everything. Harvard Business Review, 91(5), $63-72$. 
Boso, N., Cadogan, J. W., \& Story, V. M. (2012). Complementary effect of entrepreneurial and market orientations on export new product success under differing levels of competitive intensity and financial capital. International Business Review, 21(4), 667-681. https://doi.org/10.1016/j.ibusrev.2011.07.009

Boso, N., Cadogan, J. W., \& Story, V. M. (2013a). Entrepreneurial orientation and market orientation as drivers of product innovation success: A study of exporters from a developing economy. International Small Business Journal, 31(1), 57-81. https://doi.org/10.1177/0266242611400469

Boso, N., Story, V. M., \& Cadogan, J. W. (2013b). Entrepreneurial orientation, market orientation, network ties, and performance: Study of entrepreneurial firms in a developing economy. Journal of Business Venturing, 28(6), 708-727. https://doi.org/10.1016/j.jbusvent.2013.04.001

Brislin, R. W. (1970). Back-translation for cross-cultural research. Journal of Cross-Cultural Psychology, 1(3), 185-216. https://doi.org/10.1177/135910457000100301

Brouthers, K. D., Nakos, G. \& Dimitratos, P. (2015). SME entrepreneurial orientation, international performance, and the moderating role of strategic alliances. Entrepreneurship: Theory and Practice, 39(5), 1161-1187. https://doi.org/10.1111/etap.12101

Byrne, B. (2009). Structural equation modeling with AMOS: Basic concepts, applications, and programming (2nd ed). N.Y.: Routledge Taylor \& Francis Group.

Calantone, R. J., Cavusgil, S. T., \& Zhao, Y. (2002). Learning orientation, firm innovation capability, and firm performance. Industrial Marketing Management, 31(6), 515-524. https://doi.org/10.1016/S0019-8501(01)00203-6

Caruana, A., Ewing, M. T., \& Ramaseshan, B. (2002). Effects of some environmental challenges and centralization on the entrepreneurial orientation and performance of public 
sector entities. Service Industries Journal, 22(2), 43-58. https://doi.org/10.1080/714005076

Casillas, C. J., \& Moreno, M. A. (2010). The relationship between entrepreneurial orientation and growth: The moderating role of family involvement. Entrepreneurship and Regional Development, 22(3-4), 265-91. https://doi.org/10.1080/08985621003726135

Chang, S.-J., van Witteloostuijn, A., \& Eden, L. (2010). From the editors: Common method variance in international business research. Journal of International Business Studies, 41(2), 178-184. https://doi.org/10.1057/jibs.2009.88

Cheung, G. W. \& Rensvold, R. B. (2002). Evaluating goodness-of-fit indexes for testing measurement invariance. Structural Equation Modeling: A Multidisciplinary Journal, 9(2), 233-255. https://doi.org/10.1207/S15328007SEM0902_5

Cooper, G. (2000). Strategic marketing planning for radically new products. Journal of Marketing, 64(1), 1-16. https://doi.org/10.1509/jmkg.64.1.1.17987

Covin J. G., \& Lumpkin, G. T. (2011). Entrepreneurial orientation theory and research: Reflections on a needed construct. Entrepreneurship: Theory and Practice, 35(5), 855872. https://doi.org/10.1111/j.1540-6520.2011.00482.x

Covin, J. G., \& Miles, M. P. (1999). Corporate entrepreneurship and the pursuit of competitive advantage. Entrepreneurship: Theory and Practice, 23(3), 47-63. https://doi.org/10.1177/104225879902300304

Covin, J. G., \& Slevin, D. P. (1989). Strategic management of small firms in hostile and benign environments. Strategic Management Journal, 10(1), 75-87. https://doi.org/10.1002/smj.4250100107

Delmar, F., Davidsson, P., \& Gartner, W. (2003). Arriving at the high-growth firm. Journal of Business Venturing, 18(2), 189-216. DOI: 10.1016/S0883-9026(02)00080-0 
Deshpandé, R., Grinstein, A., \& Ofek, E. (2012). Strategic orientations in a competitive context: The role of strategic orientation differentiation. Marketing Letters, 23(3), 629643. https://doi.org/10.1007/s11002-012-9167-4

Deutscher, F., Zapkau, F. B., Schwens, C., Baum, M., \& Kabst, R. (2016). Strategic orientations and performance: A configurational perspective. Journal of Business Research, 69(2), 849-861. https://doi.org/10.1016/j.jbusres.2015.07.005

Dutta, D. K., Gupta, V. K., \& Chen, X. (2016). A tale of three strategic orientations: A moderated-mediation framework of the impact of entrepreneurial orientation, market orientation, and learning orientation on firm performance. Journal of Enterprising Culture, 24(3), 313-348. https://doi.org/10.1142/S0218495816500126

Eggers, F., Kraus, S., Hughes, M., Laraway, S., \& Snycerski, S. (2013). Implications of customer and entrepreneurial orientations for SME growth. Management Decision, 51(3), 524-546. https://doi.org/10.1108/00251741311309643

Engelen, A., Gupta, V., Strenger, L., \& Brettel, M. (2015). Entrepreneurial orientation, firm performance, and the moderating role of transformational leadership behaviors. Journal of Management, 41(4), 1069-1097. https://doi.org/10.1177/0149206312455244

Ennen, E., \& Richter, A. (2010). The whole is more than the sum of its parts- or is it? A Review of the empirical literature on complementarities in organizations. Journal of Management, 36(1), 207-233. https://doi.org/10.1177/0149206309350083

Farrell, M. A. (2000). Developing a market-oriented learning organization. Australian Journal of Management, 25(2), 201-222. https://doi.org/10.1177/031289620002500205

Farrell, M. A., \& Oczkowski, E. (2002). Are market orientation and learning orientation necessary for superior organizational performance? Journal of Market-Focused Management, 5(3), 197-217. https://doi.org/10.1023/A:1022990622706 
Franke, N., Von Hippel, E., \& Schreier, M. (2006). Finding commercially attractive user innovations: A test of lead-user theory. Journal of Product Innovation Management, 23, 301-315. https://doi.org/10.1111/j.1540-5885.2006.00203.x

Gatignon, H., \& Xuereb, M. (1997). Strategic orientation of the firm and new product performance. Journal of Marketing Research, 34(1), 77-90. DOI: 10.2307/3152066

George, B. A. (2011). Entrepreneurial orientation: A theoretical and empirical examination of the consequences of differing construct representations. Journal of Management Studies, 48(6), 1291-1313. https://doi.org/10.1111/j.1467-6486.2010.01004.X

Gerbing, D., \& Anderson, J. (1988). An updated paradigm for scale development. Incorporating unidimensionality and its assessment. Journal of Marketing Research, 25(2), 186-192. DOI: 10.2307/3172650

Gnizy, I., Baker, W. E., \& Grinstein, A. (2014). Proactive learning culture. A dynamic capability and key success factor for SMEs entering foreign markets. International Marketing Review, 31(5), 477-505. https://doi.org/10.1108/IMR-10-2013-0246

Grande, J., Madsen, E. L., \& Borch, O. J. (2011). The relationship between resources, entrepreneurial orientation and performance in farm-based ventures. Entrepreneurship and Regional Development, 23(3-4), 89-111. https://doi.org/10.1080/08985620903183710

Grinstein, A. (2008). The relationships between market orientation and alternative strategic orientations: A meta-analysis. European Journal of Marketing, 42(1/2), 115-134. https://doi.org/10.1108/03090560810840934

Gupta, V. K., Atav, G., Dutta, D. K. (2017). Market orientation research: a qualitative synthesis and future research agenda. Review of Managerial Science, https://doi.org/10.1007/s11846-017-0262-z. 
Gupta, V. K., Dutta, D. K., \& Chen, X. (2014). Entrepreneurial orientation capability and firm performance under conditions of organizational learning. Journal of Managerial Issues, 26(2), 157-173. http://www.jstor.org/stable/43488947

Gupta, V.K., \& Gupta, A. (2015). Relationship between entrepreneurial orientation and firm performance in large organizations over time. Journal of International Entrepreneurship, 13, 7-27. https://doi.org/10.1007/s10843-014-0138-0

Hakala, H. (2011). Strategic orientations in management literature: Three approaches to understanding the interaction between market, technology, entrepreneurial and learning orientations. International Journal of Management Reviews, 13(2), 199-217. https://doi.org/10.1111/j.1468-2370.2010.00292.x

Hakala, H., \& Kohtamäki, M. (2011). Configurations of entrepreneurial- customer- and technology orientation. International Journal of Entrepreneurial Behaviour \& Research, 17(1), 64-81. https://doi.org/10.1108/13552551111107516

Ho, J., Plewa, C., \& Lu, V. N. (2016). Examining strategic orientation complementarity using multiple regression analysis and fuzzy set QCA. Journal of Business Research, 69(6), 2199-2205. https://doi.org/10.1016/j.jbusres.2015.12.030

Hu, L. T., \& Bentler, P. M. (1999). Cutoff criteria for fit indexes in covariance structure analysis: Conventional criteria versus new alternatives. Structural equation modeling: A multidisciplinary journal, 6(1), 1-55. https://doi.org/10.1080/10705519909540118

Hult, G. T. M., Hurley, R. F., \& Knight, G. A. (2004). Innovativeness: Its antecedents and impact on business performance. Industrial Marketing Management, 33(5), 429-438. https://doi.org/10.1016/j.indmarman.2003.08.015

Hult, G. T. M., \& Ketchen, D. J. (2001). Does market orientation matter?: A test of the relationship between positional advantage and performance. Strategic Management journal, 22(9), 899-906. https://doi.org/10.1002/smj.197 
Hult, G. T. M., Ketchen, D. J., \& Arrfelt, M. (2007). Strategic supply chain management: Improving performance through a culture of competitiveness and knowledge development. Strategic Management Journal, 28(10): 1035-1052. https://doi.org/10.1002/smj.627

Hult, G. T. M., Snow, C. C., \& Kandemir, D. (2003). The role of entrepreneurship in building cultural competitiveness in different organizational types. Journal of Management, 29(3), 401-426. doi:10.1016/S0149-2063(03)00017-5

Keith, T., \& Stephen, A. (2006). The learning organisation: A meta-analysis of themes in $\begin{array}{lll}\text { literature. } & \text { Learning } & \text { Organization, }\end{array}$ https://doi.org/10.1108/09696470610645467

Kirca, A. H., Jayachandran, S., \& Bearden, W. O. (2005). Market orientation: A metaanalytic review and assessment of its antecedents and impact on performance. Journal of Marketing, 69(2), 24-41. https://doi.org/10.1509/jmkg.69.2.24.60761

Kohli, A. K., \& Jaworski, B. J. (1990). Market orientation: The construct, research propositions, and managerial implications. Journal of Marketing, 54(2), 1-18. http://dx.doi.org/10.2307/1251866

Kraft, P. S., \& Bausch, A. (2016). How do transformational leaders promote exploratory and exploitative innovation? Examining the black box through MASEM. Journal of Product Innovation Management, 33(6), 687-707. https://doi.org/10.1111/jpim.12335

Kropp, F., Lindsay, N. J., \& Shoham, A. (2006). Entrepreneurial, market, and learning orientations and international entrepreneurial - business venture performance in South African firms. International Marketing Review, 23(5), 504-523. https://doi.org/10.1108/02651330610703427

Kumar, V., Jones, E., Venkatesan, R., \& Leone, R. P. (2011). Is market orientation a source of sustainable competitive advantage or simply the cost of competing? Journal of Marketing, 75(1), 16-30. https://doi.org/10.1509/jmkg.75.1.16 
Lafferty, B. A., Hult, G., \& Thomas, M. (2001). A synthesis of contemporary market orientation perspectives. European Journal of Marketing, 35(1), 92-109. https://doi.org/10.1108/03090560110363364

Laukkanen, T., Nagy, G., Hirvonen, S., Reijonen, H., \& Pasanen, M. (2013). The effect of strategic orientations on business performance in SMEs A multigroup analysis comparing Hungary and Finland. International Marketing Review, 30(6), 510-535. https://doi.org/10.1108/IMR-09-2011-0230

Law, K. S., \& Wong, C. S. (1999). Multidimensional constructs in structural equation analysis: An illustration using the job perception and job satisfaction constructs. Journal of Management, 25(2), 143-160. https://doi.org/10.1016/S0149-2063(99)80007-5

Lechner, C., \& Gudmundsson, S. V. (2014). Entrepreneurial orientation, firm strategy and small firm performance. International Small Business Journal, 32(1), 36-60. https://doi.org/10.1177/0266242612455034

Li, Y., Wei, Z., \& Liu, Y. (2010). Strategic orientations, knowledge acquisition, and firm performance: The perspective of the vendor in cross-border outsourcing. Journal of Management Studies, 47(8), 1457-1482. $\quad$ https://doi.org/10.1111/j.1467$\underline{6486.2010 .00949 . x}$

Liu, S. S., Luo, X., \& Shi, Y. Z. (2002). Integrating customer orientation, corporate entrepreneurship, and learning orientation in organizations-in-transition: An empirical study. International Journal of Research in Marketing, 19(4), 367-382. https://doi.org/10.1016/S0167-8116(02)00098-8

Lomberg, C., Urbig, D., Stöckmann, C. Marino, L. D., \& Dickson, P. H. (2017). Entrepreneurial orientation: The dimensions' shared effects in explaining firm performance. Entrepreneurship: Theory and Practice, 41(6), 973-998. https://doi.org/10.1111/etap.12237 
Lonial, S. C., \& Carter, R. E. (2015). The impact of organizational orientations on medium and small firm performance: A resource-based perspective. Journal of Small Business Management, 53(1), 94-113. https://doi.org/10.1111/jsbm.12054

Lumpkin, G. T., \& Dess, G. G. (1996). Clarifying the entrepreneurial orientation construct and linking it to performance. Academy of Management Review, 21(1), 135-172. DOI: $10.2307 / 258632$

Marsh, H. W., \& Hocevar, D. (1985). Application of confirmatory factor analysis to the study of self-concept: First and higher order factors models and their invariance across groups. Psychological Bulletin, 97(3), 562-582. http://dx.doi.org/10.1037/0033-2909.97.3.562

Miller, D. (2011). Miller (1983) revisited: A reflection on EO research and some suggestions for the future. Entrepreneurship: Theory and Practice, 35(5), 873-894. https://doi.org/10.1111/j.1540-6520.2011.00457.x

Mood, A. M. (1971). Partitioning variance in multiple regression analyses as a tool for developing learning models. American Educational Research Journal, 8(2), 191-202. https://doi.org/10.3102/00028312008002191

Morgan, R. E., \& Berthon, P. (2008). Market orientation, generative learning, innovation strategy and business performance inter-relationships in bioscience firms. Journal of Management Studies, 45(8), 1329-1353. $\quad$ https://doi.org/10.1111/j.1467$\underline{6486.2008 .00778 . x}$

Narver, J., \& Slater, S. (1990). The effect of a market orientation on business profitability. Journal of Marketing, 54(4), 20-35. DOI: 10.2307/1251757

Nguyen, T. D., Barrett, N. J., \& Fletcher, R. (2006). Information internalisation and internationalisation-evidence from Vietnamese firms. International Business Review, 15(6), 682-701. https://doi.org/10.1016/j.ibusrev.2006.09.001 
Noble, C. H., Sinha, R. K., \& Kumar, A. (2002). Market orientation and alternative strategic orientations: a longitudinal assessment of performance implications. Journal of Marketing, 66(4), 25-39. https://doi.org/10.1509/jmkg.66.4.25.18513

O'Brien, R. M. (2007). A caution regarding rules of thumb for variance inflation factors. Quality \& Quantity, 41(5), 673-690. https://doi.org/10.1007/s11135-006-9018-6

Rauch, A., Wiklund, J., Lumpkin, G. T., \& Frese, M. (2009). Entrepreneurial orientation and business performance: An assessment of past research and suggestions for the future. Entrepreneurship Theory and Practice, 33(3), 761-787. https://doi.org/10.1111/j.1540$\underline{6520.2009 .00308 . x}$

Rothaermel, F. T. (2008). Competitive advantage in technology intensive industries. In G. D. Libecap, \& M. C. Thursby (Eds.), Advances in the study of entrepreneurship, innovation and economic growth (pp. 201-225). Emerald Group Publishing Limited, Bingley.

Seibold, D. R., \& McPhee, R. D. (1979). Commonality analysis: A method for decomposing explained variance in multiple regression analysis. Human Communication Research, 5(4), 355-365. https://doi.org/10.1111/j.1468-2958.1979.tb00649.x

Shirokova, G., Bogatyreva, K., Beliaeva, T., \& Puffer, S. M. (2016). Entrepreneurial orientation and firm performance in different environmental settings: Contingency and configurational approaches. Journal of Small Business and Enterprise Development, 23(3), 703-727. https://doi.org/10.1108/JSBED-09-2015-0132

Shirokova, G., Vega, G., \& Knatko, D. (2015). Crossing the threshold from founder management to professional management in Russian firms: An institutional perspective. International Journal of Entrepreneurial Behaviour and Research, 21(1), 76-106. https://doi.org/10.1108/IJEBR-05-2014-0092 
Sinkula, J., Baker, W., \& Noordewier, T. (1997). A framework for market-based organizational learning: Linking values, knowledge, and behavior. Journal of the Academy of Marketing Science, 25(4), 305-318. https://doi.org/10.1177/0092070397254003

Slater, S. F., \& Narver, J. C. (2000). The positive effect of a market orientation on business profitability: A balanced replication. Journal of Business Research, 48(1): 69-73. https://doi.org/10.1016/S0148-2963(98)00077-0

Slater, S. F., \& Narver, J. C. (1995). Market orientation and the learning organization. Journal of Marketing, 59(3), 63-74. DOI: 10.2307/1252120

Soininen, J., Martikainen, M., Puumalainen, K., \& Kyläheiko, K. (2012). Entrepreneurial orientation: Growth and profitability of Finnish small-and medium-sized enterprises. International Journal of Production Economics, 140(2), 614-621. DOI: 10.1016/j.ijpe.2011.05.029

Song, M., Kawakami, T., \& Stringfellow, A. (2010). A cross-national comparative study of senior management policy, marketing-manufacturing involvement, and innovation performance. Journal of Product Innovation Management, 27(2), 179-200. https://doi.org/10.1111/j.1540-5885.2010.00709.x

Tanriverdi, H., \& Lee, C-H. (2008). Within-industry diversification and firm performance in the presence of network externalities: Evidence from the software industry. Academy of Management Journal, 51(2), 381-397. https://doi.org/10.5465/amj.2008.31767300

Tanriverdi, H., \& Venkatraman, N. (2005). Knowledge relatedness and the performance of multibusiness firms. Strategic Management Journal, 26(2), 97-119. https://doi.org/10.1002/smj.435

Teece, D. J. (2007). Explicating dynamic capabilities: The nature and microfoundations of (sustainable) enterprise performance. Strategic Management Journal, 28(13), 1319-1350. https://doi.org/10.1002/smj.640 
Tse, A. C. B. (1998). Comparing the response rate, response speed and response quality of two methods of sending questionnaires: E-mail vs. mail. Journal of the Market Research Society, 40(4), 353-361. http://dx.doi.org/10.1177/147078539804000407

Vandenberg, R. J., \& Lance, C. E. (2000). A review and synthesis of the measurement invariance literature: Suggestions, practices, and recommendations for organizational research. Organizational Research Methods, 3(1), 4-70. https://doi.org/10.1177/109442810031002

Vij, S., \& Bedi, H. S. (2012). Relationship between entrepreneurial orientation and business performance: A review of literature. IUP Journal of Business Strategy, 9(3), 17-31. https://ssrn.com/abstract=2179844

Wales, W. J. (2016). Entrepreneurial orientation: A review and synthesis of promising research directions. International Small Business Journal, 34(1), 3-15. https://doi.org/10.1177/0266242615613840

Wang, C. L. (2008). Entrepreneurial orientation, learning orientation, and firm performance. Entrepreneurship: Theory and Practice, 32(4), 635-657. https://doi.org/10.1111/j.1540$\underline{6520.2008 .00246 . x}$

Wiklund, J., \& Shepherd, D. (2005). Entrepreneurial orientation and small business performance: A configurational approach. Journal of Business Venturing, 20(1), 71-91. https://doi.org/10.1016/j.jbusvent.2004.01.001

Wiklund, J., \& Shepherd, D. (2011). Where to from here? EO-as-experimentation, failure, and distribution of outcomes. Entrepreneurship: Theory and Practice, 35(5), 925-946. https://doi.org/10.1111/j.1540-6520.2011.00454.x

Yilmaz, C., Alpkan, L., \& Ergun, E. (2005). Cultural determinants of customer- and learningoriented value systems and their joint effects on firm performance. Journal of Business Research, 58(10), 1340-1352. https://doi.org/10.1016/j.jbusres.2004.06.002 
Zhou, K. Z., Yim, C. K. B., \& Tse, D. K. (2005). The effects of strategic orientations on technology- and market-based breakthrough innovations. Journal of Marketing, 69(2), 4260. https://doi.org/10.1509/jmkg.69.2.42.60756 


\section{Table 1}

Constructs, measurement items and reliability and validity tests.

Variable

Market orientation (Narver \& Slater, 1990)

Customer orientation: $\mathrm{CR}=0.74 ; \mathrm{AVE}=0.49$.

1. We constantly monitor our level of commitment and orientation to serving customers' needs.

2. Our business strategies are driven by our beliefs about how we can create greater value for customers.

3. Our strategy for competitive advantage is based on our understanding of customer needs. $^{\mathrm{a}}$

4. Our business objectives are driven primarily by customer satisfaction.

5. We give close attention to after-sales service. ${ }^{a}$

6. We measure customer satisfaction systematically and frequently. ${ }^{\mathrm{a}}$

Competitor orientation: $\mathrm{CR}=0.75 ; \mathrm{AVE}=0.50$.

7. The top management team regularly discusses competitors' strengths and strategies.

8. We target customers and customer groups where we have, or can develop, a competitive advantage. ${ }^{\mathrm{a}}$

9. Our salespeople regularly share information within our business concerning competitors' strategies.

10. We rapidly respond to competitive actions that threaten us.

Inter-functional coordination: $\mathrm{CR}=0.83 ; \mathrm{AVE}=0.54$.

11. Our top managers from every function regularly visit our current and prospective customers. $^{\text {a }}$

12. We freely communicate information about our successful and unsuccessful customer experiences across all business functions.

13. All of our business functions (e.g. marketing/sales, manufacturing, R\&D, finance/accounting, etc.) are integrated in serving the needs of our target markets.

14. All of our managers understand how everyone in our company can contribute to creating customer value.

15. All of our business functions share resources with other business units (information, etc.).

Entrepreneurial orientation (Covin \& Slevin, 1989)

Innovativeness: $\mathrm{CR}=0.82 ; \mathrm{AVE}=0.60$.

1. In general, the top managers of my firm favor a strong emphasis on $R \& D$, technological leadership, and innovations.

2. My firm has marketed very many new lines of products or services in the past five years.

3. Changes in product or service lines have usually been quite dramatic.

Proactiveness: $\mathrm{CR}=0.82 ; \mathrm{AVE}=0.70$

4. In dealing with its competitors, my firm typically initiates actions which competitors then respond to.

5. In dealing with its competitors, my firm is very often the first business to introduce new products/services, administrative techniques, operating technologies, etc.

6. In dealing with its competitors, my firm typically adopts a very competitive, 'undothe-competitors' posture. ${ }^{\mathrm{a}}$

Risk-taking: $\mathrm{CR}=0.81 ; \mathrm{AVE}=0.58$.

7. In general, the top managers of my firm have a strong proclivity for high-risk projects (with chances of very high returns).

8. In general, the top managers of my firm believe that owning to the nature of the environment, bold, wide-ranging acts are necessary to achieve the firm's objectives.

9. When confronted with decision-making situations involving uncertainty, my firm 
typically adopts a bold, aggressive posture in order to maximize the probability of exploiting potential opportunities.

Learning orientation (Sinkula et al., 1997)

Commitment to learning: $\mathrm{CR}=0.91 ; \mathrm{AVE}=0.71$.

1. Managers basically agree that our organization's ability to learn is the key to our competitive advantage.

2. The basic values of this organization include learning as key to improvement.

3. The sense around here is that employee learning is an investment, not an expense.

4. Learning in my organization is seen as a key commodity necessary to guarantee organizational survival.

Shared vision: $\mathrm{CR}=0.89 ; \mathrm{AVE}=0.68$.

5. There is a commonality of purpose in my organization.

6. There is total agreement on our organizational vision across all levels, functions and divisions.

7. All employees are committed to the goals of this organization.

8. Employees view themselves as partners in charting the direction of the organization. Open-mindedness: $\mathrm{CR}=0.69 ; \mathrm{AVE}=0.53$.

9. We are not afraid to reflect critically on the shared assumptions we have made about our customers.

10. Personnel in this enterprise realize that the very way they perceive the marketplace must be continually questioned.

11. We rarely collectively question our own biases about the way we interpret customer information. (reverse scored). ${ }^{\mathrm{a}}$

Notes: ${ }^{a}$ item omitted as a result of CFA.

$\mathrm{CR}=$ composite reliability; AVE = average variance extracted.

Table 2

Measurement models and fit indices.

\begin{tabular}{lcccccc}
\hline CFA Models & $\chi^{2} / \mathrm{df}$ & $p$-value & GFI & CFI & SRMR & RMSEA \\
\hline Measurement model 1 & 1.92 & 0.00 & 0.95 & 0.96 & 0.05 & $0.07, p=0.15$ \\
Measurement model 2 & 1.26 & 0.21 & 0.98 & 0.99 & 0.03 & $0.04, p=0.70$ \\
Measurement model 3 & 1.52 & 0.03 & 0.96 & 0.99 & 0.04 & $0.05, p=0.50$ \\
Full measurement model & 1.78 & 0.01 & 0.96 & 0.97 & 0.05 & $0.06, p=0.27$ \\
\hline
\end{tabular}

\section{Notes:}

Measurement model 1: customer orientation, competitor orientation, inter-functional coordination.

Measurement model 2: innovativeness, proactiveness, risk-taking.

Measurement model 3: commitment to learning, shared vision, open-mindedness.

Full measurement model: all items retained in model 1 through to model 3 were modeled simultaneously.

$\chi^{2} / \mathrm{df}=$ chi squre/degree of freedom ratio; GFI = goodness of fit index; CFI = comparative fit index; SRMR = standardized root mean residual; RMSEA = root mean square error of approximation. 
Table 3

Descriptive statistics and correlations.

\begin{tabular}{llrrrrrrrrr}
\hline $\mathrm{N}$ & \multicolumn{1}{c}{ Variable } & \multicolumn{1}{c}{$\mathrm{M}$} & \multicolumn{1}{c}{ SD } & \multicolumn{1}{c}{1} & \multicolumn{1}{c}{2} & 3 & 4 & 5 & 6 & 7 \\
\hline 1 & Sales growth $_{2}$ & 29.66 & 54.96 & & & & & & & \\
2 & Firm age $^{\mathrm{a}}$ & 2.39 & 0.75 & $-0.27^{*}$ & & & & & & \\
3 & Firm size $^{\mathrm{a}}$ & 2.63 & 1.59 & $-0.15^{*}$ & $0.41^{*}$ & & & & & \\
4 & $\begin{array}{l}\text { Production } \\
5\end{array}$ & 0.26 & 0.44 & -0.01 & $0.18^{*}$ & $0.25^{*}$ & & & & \\
6 & $\begin{array}{l}\text { Services } \\
\text { Entrepreneurial }\end{array}$ & 0.46 & 0.49 & 0.07 & -0.07 & $-0.16^{*}$ & $-0.55^{*}$ & & & \\
& $\begin{array}{l}\text { orientation } \\
7\end{array}$ & 4.07 & 1.26 & $0.14^{*}$ & 0.09 & 0.12 & 0.09 & -0.12 & & \\
& $\begin{array}{l}\text { Market } \\
\text { orientation }\end{array}$ & 3.82 & 0.59 & $0.16^{*}$ & -0.09 & -0.05 & -0.05 & 0.03 & $0.44^{*}$ & \\
8 & $\begin{array}{l}\text { Learning } \\
\text { orientation }\end{array}$ & 4.97 & 1.10 & $0.17^{*}$ & $-0.17^{*}$ & $-0.21^{*}$ & -0.04 & -0.03 & $0.30^{*}$ & $0.59^{*}$ \\
\hline
\end{tabular}

Notes: significant at $* p<.05 ; \mathrm{n}=221 ; \mathrm{M}=$ mean, $\mathrm{SD}=$ standard deviation.

${ }^{a}$ Natural logarithm taken.

Table 4

Commonality analysis.

\begin{tabular}{|c|c|c|c|}
\hline & Variance decomposition & \multicolumn{2}{|c|}{ Bootstrapping } \\
\hline \multicolumn{4}{|c|}{ Unique effects } \\
\hline 1. & Entrepreneurial orientation (EO) & $0.016 \dagger$ & $(42 \%)$ \\
\hline 2. & Market orientation (MO) & 0.001 & $(2 \%)$ \\
\hline 3. & Learning orientation (LO) & 0.002 & $(6 \%)$ \\
\hline \multicolumn{4}{|c|}{ Bilaterally shared effects } \\
\hline 4. & $\mathrm{EO} \& \mathrm{MO}$ & 0.005 & $(13 \%)$ \\
\hline 5. & EO \& LO & 0.001 & $(3 \%)$ \\
\hline 6. & MO \& LO & 0.003 & $(8 \%)$ \\
\hline \multicolumn{4}{|c|}{ Commonly shared effects } \\
\hline 7. & $\mathrm{EO} \& \mathrm{MO} \& \mathrm{LO}$ & $0.010 *$ & $(26 \%)$ \\
\hline 8. & Total effect ( $=$ unique + shared effects) & $0.037 *$ & $(100 \%)$ \\
\hline
\end{tabular}

Table 5

SEM results on complementary effect of proactive learning culture on firm sales growth.

\begin{tabular}{lc}
\hline Hypothesized Effects & Regression Weights \\
\hline PLC $\rightarrow$ MO & $0.58^{* * *}$ \\
PLC $\rightarrow$ EO & $0.75^{* * *}$ \\
PLC $\rightarrow$ LO & $0.40^{* * *}$ \\
PLC $\rightarrow$ Sales growth & $0.23^{* *}$ \\
Control effects & \\
Firm age $^{\text {a }} \rightarrow$ Sales growth & $-0.26^{* * *}$ \\
Firm size & a Sales growth \\
Production $\rightarrow$ Sales growth & -0.07 \\
Services $\rightarrow$ Sales growth & 0.11 \\
\hline
\end{tabular}




\begin{tabular}{ll}
\hline Model Statistics & \\
$\chi^{2}$ & 29.88 \\
df & 14 \\
$\chi^{2} / \mathrm{df}$ & 2.13 \\
$p$-value & 0.01 \\
RMSEA & $0.07, p=0.14$ \\
SRMR & 0.06 \\
GFI & 0.97 \\
CFI & 0.95 \\
$\mathrm{R}^{2}$ & 0.14 \\
\hline
\end{tabular}

Notes: *** $p<.001 ; * * p<.01, * p<.05, \dagger p<.1$.

${ }^{\text {a N}}$ Natural logarithm taken.

\section{Table 6}

SEM results for the alternative models.

\begin{tabular}{lccccccc}
\hline \multicolumn{1}{c}{ Structural Models } & $\chi^{2} / \mathrm{df}$ & $\begin{array}{c}p- \\
\text { value }\end{array}$ & GFI & CFI & SRMR & RMSEA & $\mathrm{R}^{2}$ \\
\hline Individual effects (IE) model & 2.27 & 0.01 & 0.97 & 0.95 & 0.06 & $0.08, p=0.11$ & 0.12 \\
$\begin{array}{l}\text { Reduced model 1: IE model } \\
\text { without covariance }\end{array}$ & 10.71 & 0.00 & 0.85 & 0.50 & 0.15 & $0.21, p=0.00$ & 0.11 \\
Reduced model 2: EO & 1.49 & 0.19 & 0.99 & 0.98 & 0.05 & $0.05, p=0.45$ & 0.14 \\
Reduced model 3: MO & 0.63 & 0.67 & 1.00 & 1.00 & 0.03 & $0.00, p=0.86$ & 0.09 \\
Reduced model 4: LO & 2.76 & 0.02 & 0.98 & 0.94 & 0.06 & $0.09, p=0.10$ & 0.08 \\
Reduced model 5: EO, MO & 1.59 & 0.11 & 0.98 & 0.97 & 0.05 & $0.05, p=0.42$ & 0.14 \\
Reduced model 6: EO, LO & 2.86 & 0.00 & 0.97 & 0.91 & 0.07 & $0.09, p=0.05$ & 0.16 \\
Reduced model 7: MO, LO & 1.92 & 0.04 & 0.98 & 0.97 & 0.06 & $0.07, p=0.26$ & 0.11 \\
Complementarity model: EO, & 2.13 & 0.01 & 0.97 & 0.95 & 0.06 & $0.07, p=0.14$ & 0.14 \\
MO, LO & & & & & & & \\
\hline
\end{tabular}




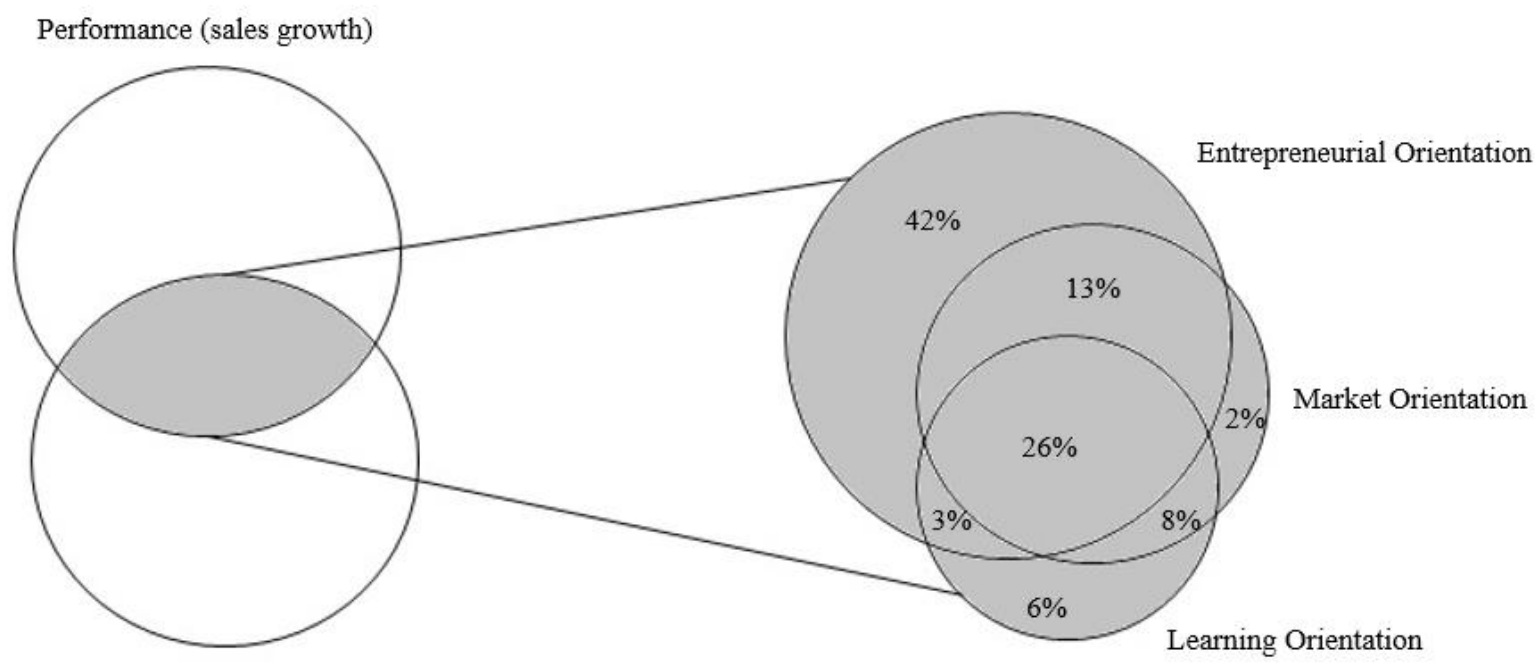

Proactive Learning Culture

Fig. 1. Graphical illustration of the commonality analysis results.

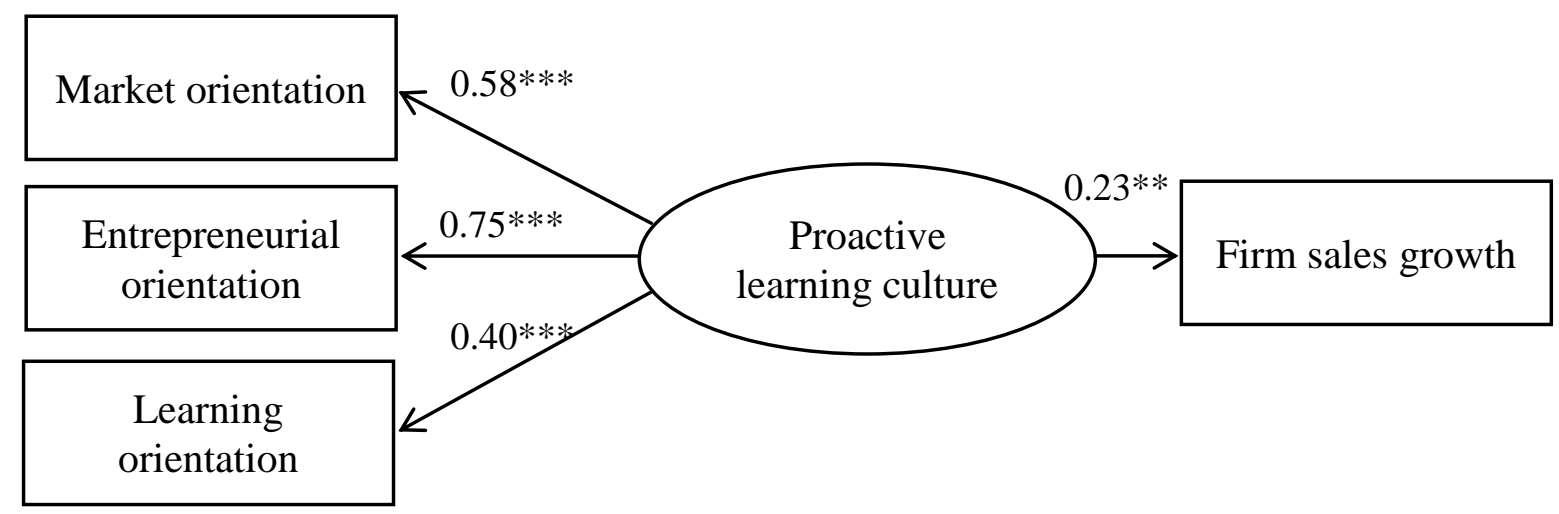

Notes: $* * * p<.001 ; * * p<.01$

Fig. 2. Graphical illustration of the SEM results ${ }^{5}$.

\footnotetext{
${ }^{5}$ We include firm size, firm age, and industry as control variables in the SEM analysis. However, for the parsimony of the graphic presentation, we abstain from displaying those. Covariations between the controls were added based on the significance of the correlations from Table 3.
} 


\section{Orienting toward sales growth? Decomposing the variance attributed to three fundamental organizational strategic orientations}

\section{Author bios}

William Wales is the Standish Chair and Associate Professor of Entrepreneurship at the University at Albany-SUNY. His research principally explores the concept of firm-level entrepreneurial orientation, strategy-making processes, and behavior. His work has been published within the Strategic Management Journal, Journal of Management Studies, Entrepreneurship: Theory and Practice, Strategic Entrepreneurship Journal, Journal of Business Research, Journal of Product Innovation Management, and the International Small Business Journal among others. He is an active member of the Academy of Management.

Tatiana Beliaeva is a Doctoral student at Lappeenranta University of Technology, Finland, in the research field of Economics and Business Administration. She received her Candidate of Economic Sciences degree from St. Petersburg University, Russia. Her primary research interests are in the area of firm-level strategic orientations and entrepreneurship. Tatiana Beliaeva is actively involved in research activities at the Centre for Entrepreneurship in St. Petersburg University.

Galina Shirokova is a Professor of Strategic and International Management Department at St. Petersburg University Graduate School of Management. Her research interests include entrepreneurship in emerging markets, entrepreneurial orientation, and student entrepreneurship. She is an author of more than 100 publications, including 60 articles in academic journals and 20 cases about Russian entrepreneurial firms.

Tatiana R. Stettler is an Assistant Professor of the Marketing and Entrepreneurship Department in Kent State University, USA. Prior to this appointment she has completed her $\mathrm{PhD}$ and worked as Senior Researcher at the Department of Management and Entrepreneurship of the University of Bern in Switzerland. Her research focusses on firmlevel strategic orientations, absorptive capacity, and complementarity.

Vishal K. Gupta is an Associate Professor at The University of Alabama. His primary research interests are in the area of entrepreneurial orientation, top management, and corporate entrepreneurship. His research has been widely presented and published in journals such as Academy of Management Review, Strategic Management Journal, Journal of Management, Journal of Applied Psychology, Journal of Business Venturing, and Entrepreneurship Theory \& Practice, among others. He is an active contributor to the Academy of Management, most recently serving as entrepreneurship track chair for the 2017 Southwest Academy of Management Conference. 